\title{
The Effect Of Plus/Minus Grading On The GPA
}

Yonah Wilamowsky, Seton Hall University, USA

Bernard H. Dickman, Hofstra University, USA

Sheldon Epstein, Seton Hall University, USA

\begin{abstract}
In recent years, an increasing number of colleges and universities have been turning away from traditional letter grading systems that limit student grades to $A, B, C, D$, and $F$ based on the presumption that grading systems with more flexibility are advantageous to both teachers and students. However, as with any rating system, before opting for a new grading system it is important to recognize that modifications may result in some, possibly unintended, consequences as well. In this paper, we discuss theoretical effects that including plus and/or minus grades may have on Grade Point Average (GPA) and analyze data from a School that implemented such a change.
\end{abstract}

Keywords: Grading Systems, Grade Inflation

\section{INTRODUCTION}

$\mathrm{n}$ recent years, an increasing number of colleges and universities have been turning away from traditional
letter grading systems with 4 or 5 categories $(\mathrm{A}, \mathrm{B}, \mathrm{C}, \mathrm{D}, \mathrm{F})$ to systems with a greater number of grade choices ${ }^{1}$. These include adding the possibility of marginal grades $(\mathrm{AB}, \mathrm{BC}, \mathrm{CD}$-halfway between the letter grades) as well as plus and/or minus grades. Within this last group, there are numerous variations: Plus only, minus only, both plus and minus, excluding the grades of A+, D-, and sometimes $\mathrm{C}-$. Various advantages have been suggested for grading systems with more flexibility. The single most important reason for including plus and minus grades is to be able to better differentiate between the performances of different students. A student with an 80 average is typically doing work at a significantly different level than one with an 88 or 89 and they should be distinguishable from one another. This will allow any interested parties, whether a graduate school or potential employer to better recognize the student with greater achievement. Simulation studies ${ }^{2}$ have shown that under certain conditions the reported grades are a more accurate reflection of student performance when using plus/minus grades. In a similar vein, the plus/minus grades may provide the student with greater motivation to do better. A student running a B in a course may feel that an A is out of reach while a B+ is within his grasp. Conversely, a student satisfied with the B, may decide to slacken off since there is no great risk of falling to a C, whereas a Bmight be a real possibility.

A less obvious reason that has been advanced for plus/minus grading is that it tends to reduce grade inflation, which has been recognized as a problem in recent years. The reasoning is as follows ${ }^{3}$. Teachers are under pressure to give higher grades wherever possible. This may result from the current culture of students as customers, greater involvement of parents in their children's college lives including grades ${ }^{4}$, and the use of student evaluations in assessing teacher performance ${ }^{5}$. This pressure causes a professor to give any benefit of the doubt to the student, and in particular, if a grade is borderline to award the higher grade. With the possibility of pluses and minuses, rather than giving an A instead of a B, a professor may give the student a B+ or an A-. A number of studies have been done which imply that grade inflation is either eliminated or reduced with the introduction of plus/minus grades $^{1,6}$. That is to say, for these schools' data, in the year following the implementation, average GPAs were reduced, and in subsequent years they either did not rise, or rose more slowly than previously. It is certainly most important for any school considering a change to recognize this effect on GPAs and the resulting implications to the 
competitiveness of its student body. It is equally important for those evaluating student grades to understand the implications of these different grading systems.

But psychology of grade inflation may not be the only factor explaining the reduction of the average GPA after the introduction of plus and/or minus grades. There are a number of different systems employed for determining the point values of plus and minus grades. Typically, after the introduction of plus and minus grades, the value of the letter grades remains the same as previously, i.e., $\mathrm{A}=4, \mathrm{~B}=3, \mathrm{C}=2, \mathrm{D}=1, \mathrm{~F}=0$. Also typically, the plus grade adds the same amount to the value as the minus grade subtracts. However, there is no uniformity as to how much this is. The most common two approaches add and subtract either 0.3 or 0.33 . That is, in the former case, for example, $\mathrm{B}+$ is 3.3 and $\mathrm{B}$ - is 2.7 and in the latter $\mathrm{B}+$ is 3.33 and $\mathrm{B}-$ is 2.67 . As long as plus and minus grades are included for each letter grade available, and assuming that the distribution of numeric grades within each letter category is symmetric, then theoretically, there is no reason to believe that there should be any change in average GPAs. In fact, simulations done using these types of assumptions ${ }^{2}$ have shown very little effect on student GPAs. Thus, any empirical changes that do occur could logically be attributed to the professor's change in grading policy - possibly an indication of the previously mentioned characteristic of grade inflation.

But very often, $\mathrm{A}+$ is either not included as an option, or its point value retains the same 4.0 as does the grade of A. This is done in order to maintain the uniformity of 4.0 as being the maximum GPA possible. Because some As will be downgraded to A- without a compensatory possibility of raising any As to a higher level, the resultant effect is the depressing of the average GPA. Analogously, many schools do not include a C- or D- as options $^{7}$. The C- may not be included, as is the case in California State University, because the minimum GPA required to maintain matriculation or to transfer to another college is often a 2.0, so they prefer not to lower the grade of $\mathrm{C}$, which represents a 2.0, to a C- which would be below 2.0. D- is often not included because of the feeling that $\mathrm{D}$ should be the minimum passing grade. Exclusion of these grades would tend to increase the average GPA since the pluses in these categories are not balanced by minuses. In addition, there is no reason to believe that the distribution of numeric grades within a letter category is symmetric. Depending on the particular distribution, overall GPAs might go up or down.

Finally, in certain schools, introduction of a greater number of grade choices has been done in either a partial or stepwise manner. That is, only plus grades or only minus grades are added. As mentioned previously, these are sometimes called $\mathrm{AB}, \mathrm{BC}, \mathrm{CD}$. The grade point values typically associate with $\mathrm{B}+$ or $\mathrm{AB}$ is 3.5 , with $\mathrm{C}+$ or $\mathrm{BC}$ is 2.5 etc. In these cases, a grade of $\mathrm{B}+$ would be given to an 85 or possibly 87 and above. Since only plus grades are available, grades can only go up and the clear result from a theoretical perspective would be to increase the overall GPA. In some schools, the two types of grade systems were added sequentially, i.e. first plus grades (excluding A+) were added and later minus grades were added. Again, it would be logical that the addition of plus grades raised GPAs, assuming the distribution of grades as given before, and the introduction of the minus grades would reduce GPAs.

\section{SETON HALL UNIVERSITY: BACKGROUND}

Seton Hall is an example of a school that introduced grade changes in stages, i.e. they introduced plus grades a number of years ago and in fall 2004 began to give minus grades as well. A special Faculty Senate committee had been tasked with making a recommendation on adding in minus grades. ${ }^{8}$ In addition to consideration of some of the same factors that we mentioned previously, the committee also looked into the practices of 22 peer schools. Of these they found that 17 were giving plus/minus grades and five were giving plus only. It was also found that the schools with higher academic rankings were using plus and minus grades. They also noted the previous findings that in most schools there was a negligible effect on grade inflation and in other institutions there may have been a slight decline in GPAs.

Since previous studies had been carried out in situations where pluses and minuses were added simultaneously, the experience of Seton Hall allows us to investigate the somewhat different case where the grades were introduced sequentially, i.e. minus grades were added after plus grades had already been available. In theory, as discussed previously this should have caused a reduction in GPAs due to the new choice of minus grades. It is 
also possible that the effect may initially be minimized because not all professors may immediately take advantage of the new grade options. The present study analyzes the data for the School of Business after plus/minus grading has been available for two years. In particular, we compare grade data for eight semesters: four before and four after the implementation of minus grades. Our working hypothesis based on theoretical considerations mentioned previously is that the analysis should show an overall reduction in GPAs after implementation. In a previous paper ${ }^{9}$ a preliminary study based on two years of Seton Hall data ( 2 semesters before the change and 2 after the change) seemed to support the overall reduction hypothesis. In this paper we see if additional years of data continue to confirm the trend.

\section{DATA \& ANALYSIS}

The grading system in effect as well as the school wide GPA for the Seton Hall School of Business for the period Fall 2002 through Spring 2006 is given in Table 1.

Table 1

Grading System and GPA for Fall 2002 through Spring 2006

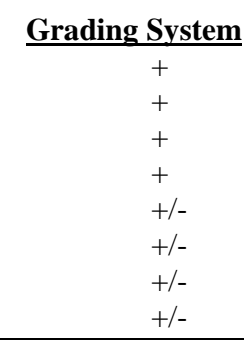

\begin{tabular}{lc} 
Semester & Average School Wide GPA \\
\cline { 2 - 2 } Fall, 2002 & 3.142 \\
Spring, 2003 & 3.138 \\
Fall, 2003 & 3.161 \\
Spring, 2004 & 3.141 \\
Fall, 2004 & 3.052 \\
Spring, 2005 & 3.099 \\
Fall, 2005 & 3.176 \\
Spring, 2006 & 3.182
\end{tabular}

In the four semesters preceding the grading change, the average school grades were quite stable, and the data tends to be in conformance with the assumption that a drop in overall GPA will occur in the year following the introduction of minus grades. However in the second year of the $+/$ - change we note a surprising result. The grades have not only not remained stable, or risen slowly, but have returned at least to where they were before the grading system change. In an effort to further analyze some of the dimensions of these changes, we divided the grade data into three groups:

Undergraduate core, Undergraduate elective, and Graduate.

The results of this analysis, given in Table 2, were quite interesting and may shed some light on the process as well as psychology of grading. The comparable chart for the eight semesters broken down by the three categories is as follows:

Table 2

Grading System and GPA for Fall 2002 through Spring 2006 by Course Type

\begin{tabular}{|c|c|c|c|}
\hline$\underline{\text { Semester }}$ & UG core & $\underline{\text { UG elective }}$ & Graduate \\
\hline$\overline{\text { Fall, } 2002}$ & 2.93 & 3.18 & 3.55 \\
\hline Spring, 2003 & 2.89 & 3.16 & 3.60 \\
\hline Fall, 2003 & 2.97 & 3.15 & 3.64 \\
\hline Spring, 2004 & 2.89 & 3.19 & 3.59 \\
\hline Fall, 2004 & 2.90 & 3.05 & 3.49 \\
\hline Spring, 2005 & 2.93 & 3.11 & 3.47 \\
\hline Fall, 2005 & 3.00 & 3.25 & 3.53 \\
\hline Spring, 2006 & 2.94 & 3.32 & 3.57 \\
\hline
\end{tabular}


Upon inspecting the first year following the introduction of minus grades, we note the following. Of the somewhat modest decline seen in the overall summary data, analysis of the component groups indicates that there is a considerable difference between these groups. While the change in grading systems displayed no noticeable effect on GPAs of the undergraduate core courses, both the graduate and undergraduate elective courses showed a clear decline between the Spring and Fall, 2004 semesters when the minus grades were introduced. Based on the previous discussion, how much of a decline in grades is to be expected with the introduction of minus grades? This is impossible to determine exactly without knowing the individual grading schemes and grade distributions for each class for these two semesters. But with some reasonable assumptions, we attempted to approximate what the 200304 grades would have been had there been minus grades available and to compare these results to the 2004-05 grades.

We began by assuming the + and $+/$ - plus grading schemes as given in Table 3 .

Table 3

+ and +/- Grading Assignments and GPA Values

\begin{tabular}{|c|c|c|}
\hline \multicolumn{3}{|c|}{+ System } \\
\hline Numerical Range & Letter & GPA \\
\hline & Grade & Value \\
\hline $90-100$ & A & 4.0 \\
\hline $85-89$ & $\mathrm{~B}+$ & 3.5 \\
\hline $80-84$ & B & 3.0 \\
\hline $75-79$ & $\mathrm{C}+$ & 2.5 \\
\hline $70-74$ & $\mathrm{C}$ & 2.0 \\
\hline $65-69$ & D+ & 1.5 \\
\hline $60-64$ & $\mathrm{D}$ & 1.0 \\
\hline$-\quad 59$ & $\mathrm{~F}$ & 0.0 \\
\hline
\end{tabular}

\begin{tabular}{cccl}
\multicolumn{4}{c}{+ /- System } \\
Numerical Range & $\begin{array}{c}\text { Letter } \\
\text { Grade }\end{array}$ & $\begin{array}{l}\text { GPA } \\
\text { Value }\end{array}$ \\
$93-100$ & A & 4.0 \\
$90-92$ & A- & 3.67 \\
$87-89$ & B+ & 3.33 \\
$83-86$ & B & 3.0 \\
$80-82$ & B- & 2.67 \\
$77-79$ & C+ & 2.33 \\
$73-76$ & C & 2.0 \\
$70-72$ & C- & 1.67 \\
$65-69$ & D+ & 1.33 \\
$60-64$ & D & 1.0 \\
-59 & F & 0.0
\end{tabular}

Although not all faculty use this scheme, these are the numerical-letter assignments most often used. We further assumed that grades are uniformly distributed within each group in the plus only scheme (90-100, 85-89, 80$84 \ldots$... While the grades will not necessarily be uniformly distributed, over the small ranges chosen, the differences should not have a significant effect. In any event, no other assumption has greater validity. Using these assumptions, an expected value was calculated using the grading distributions for each subgroup of grades for the 2003-2004 academic year to see what the grades might have been had minus grades been available. For example, assume there were $100 \mathrm{~B}+$ grades in Fall, 2003 which used only plus grades, and counted as 3.5 in the GPA. These would represent grades between 85 and 89 which we assume to be uniformly distributed. Had these grades been given in the Fall of 2004, using the plus/minus scheme, then any grades between 85 and 86 would have gotten a B, at a GPA contribution of 3.0, but those between 87 and 89 would be a B+ with a contribution of 3.33. Thus the 100 scores would, on the average, have had $60 \mathrm{~B}+\mathrm{s}$ and $40 \mathrm{Bs}$, for a combined GPA of $0.60 * 3.33+0.40 * 3.0=3.20$. Using this analysis, if minus grades had been available, and with no other grade changes by professors, GPAs for the 20032004 Academic Year would have been:

\begin{tabular}{|c|c|c|c|}
\hline$\underline{\text { Semester }}$ & $\underline{\text { UG core }}$ & $\underline{\text { UG elective }}$ & Graduate \\
\hline Fall, 2003 & 2.78 & 2.97 & 3.47 \\
\hline Spring, 2004 & 2.71 & 3.02 & 3.41 \\
\hline
\end{tabular}


Comparing these to the actual GPAs for Fall, 2004 and Spring, 2005 when minus grades were first available, we find very different results in the three categories. The graduate is quite close to expectation, the undergraduate electives are somewhat close and the core courses are much further away from what might have been expected

As mentioned previously, the expectation of these results assumes that the assignment of grades would be comparable after the introduction of minus grades without any other considerations on the part of the faculty. However, it is apparent that the undergraduate core courses are being treated differently by professors than are the elective and graduate courses. Why is not clear. We may conjecture that higher level, more demanding courses were treated more seriously and rigorously on the part of the grader. The core courses seem to have had a fairly constant grade distribution no matter which grading system is in effect. Perhaps the teachers adjusted for the new grades, in order not to affect the student.

The results of the second year following the grade change were even more surprising. As noted previously, the overall average grades bounced back to where they had been before the grade change. This was not anticipated. In looking at the three individual groups, we see that while the undergraduate core remained steady over the entire eight semesters, and the graduate returned to their previous average, the undergraduate electives returned at least to their previous average if not higher. Again, we might be led to believe that with the year's experience, professors adjusted to the new grading system to bring grades in line with what they had been previously. But an analysis of individual departments shows that there might be a more complex interaction at play. We looked at the behavior of individual departments over the course of the eight semesters in each of the three categories.

Figure 1 presents graphs of the average GPAs for the eight semesters, broken down by course level as well as by the largest departments. We can immediately observe the previously noted point that undergraduate core is relatively stable, while the undergraduate electives and graduate courses dip at the Fall, 2004 semester (when minuses were introduced) and then begin to rise. However, when looking at the graphs for individual departments, we see that these effects are not at all uniform across departments. In fact, the only department that the GPA uniformly drops in the Fall, 2004 semester at all three levels is Accounting. At the graduate level, the other three large departments appear to have had little effect from the grade change. At the undergraduate level, grades in Management (a large department) rise during the changeover period, while those in Finance and Marketing fall in some areas, and rise or show no change in others. In fact, removal of the Accounting grades from the summary analysis, would eliminate the significant decrease noted with the introduction of minus grades.

What might explain the different result for the Accounting department? How is it that the introduction of minus grades did not seem to affect the other departments in the same way? We may conjecture that since Accounting is currently the strongest and most sought after major in the School of Business, professors did not feel the need to adjust their grading patterns. Additionally, Accounting is the only major with its own accreditation and leading toward objective CPA exams that must be passed by its graduates. Other departments might be more inclined to adjust their grading procedures to keep grades at least level if not increasing.

\section{CONCLUSION}

The analysis of the available data from a study of 4 years at Seton Hall University has led to many conjectures but few hard conclusions. It is clear, however, that grading processes with changing grading systems are complex, with interactions between course levels and departments. Further research is required to verify what the overall trends and interactions are so that schools contemplating changes in their grading system will be better informed as to other changes that they may expect. 
Figure 1

GPAs Over Eight Semesters Broken Down by Largest Departments
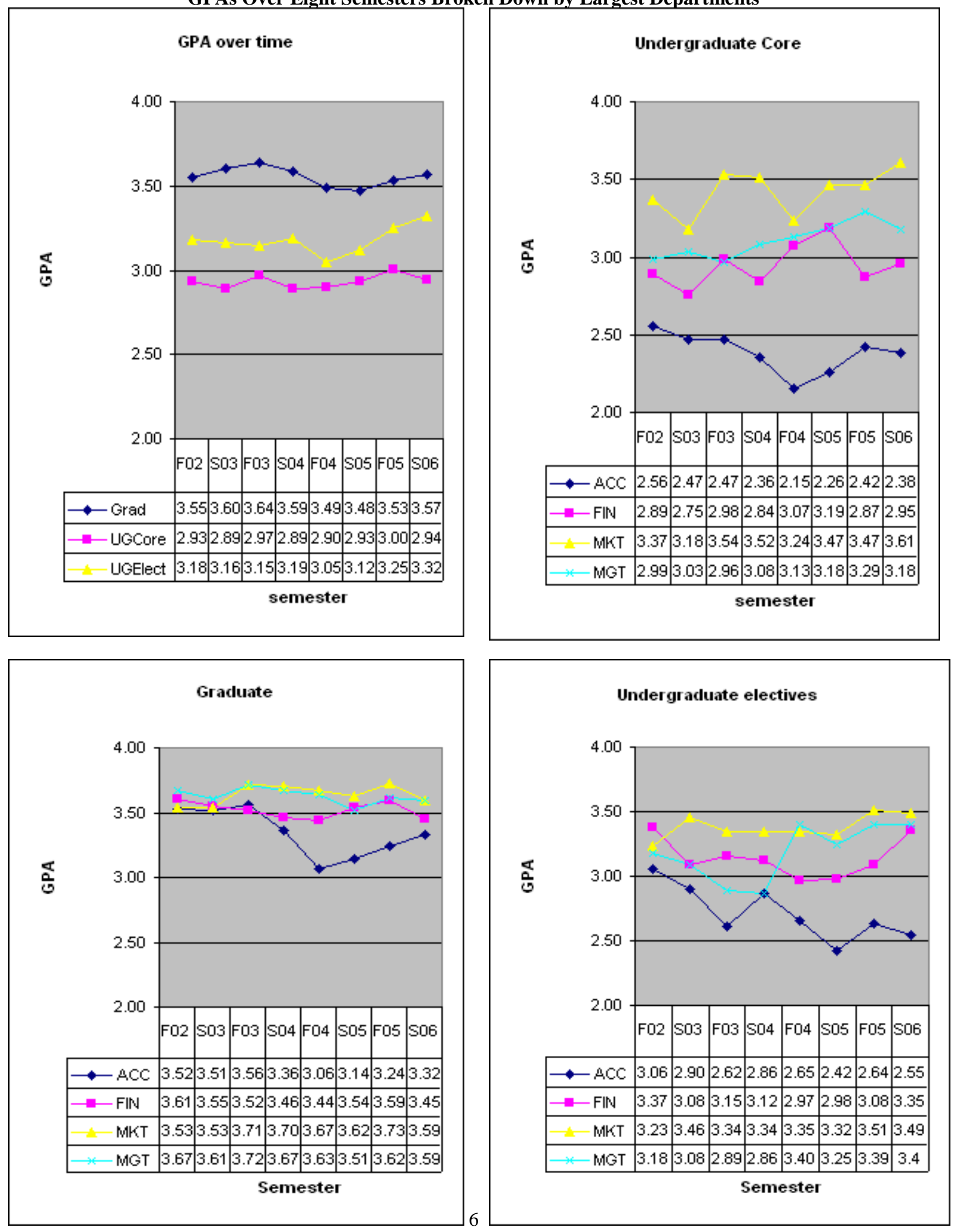


\section{REFERENCES}

${ }^{1}$ Quann, C. J.(1987). Plus-Minus Grading: A Case Study and National Implications (pp1-17). Washington D.C.: American Association of Collegiate Registrars and Admissions Officers.

${ }^{2}$ Matthews, R. (1997). Evaluation of the Plus/Minus Grading System: A Computer Model. [Online] Available: http://www.wfu.edu/matthews/plus_minus/plus_minus.html

${ }^{3}$ Bressette, A. (2002) Arguments for Plus/Minus Grading: A Case Study. Educational Research Quarterly, Vol. 25, No. 3.

${ }^{4}$ New York Times (July 31, 2005). Back to Campus; First-Year Help: For Parents Only, Education Life Supplement, page 32 .

${ }^{5}$ Bowen, Roger W. (November-December, 2006). Bs Are Rare. Academe, p. 87.

${ }^{6}$ Gosselin, C. L. (1997). Plus Minus Grading Study, Fall, 1994 through Spring, 1997. (Raleigh:University Planning and Analysis for North Carolina State University).

${ }^{7}$ The Academic Senate for California Community Colleges, (1996). "Plus and Minus Grading Options: Towards Accurate Student Performance Evaluations" [Online] Available:

Http://www.academicsenate.cc.ca.us/publications/Papers/Plus_minus_grading.html

${ }^{8}$ Faculty Senate Special Committee, Seton Hall University (2003).

${ }^{9}$ Wilamowsky, Y., Epstein, S. \& Dickman, B. January, 2006, The Relationship Between GPA and Grading Systems", Teaching and Learning Conference 2006 Proceedings, Orlando, Florida 


\section{NOTES}

